\title{
Rechtspopulismus, Integration und Migrationspolitik in Nordeuropa - Die Volksheime unter Druck
}

\author{
Sven Jochem
}

\section{Rechtspopulismus in den sozialdemokratischen Hochburgen Europas}

Die nordischen Länder ${ }^{1}$ können kaum als klassische Einwanderungsgesellschaften bezeichnet werden. Eine Arbeitsmigration, wie sie in Deutschland seit den ausgehenden 196oer Jahren zu beobachten ist, fand im Norden in diesem Ausmaß kaum statt. Seit 1954 existiert jedoch im Norden ein gemeinsamer Arbeitsmarkt mit unbeschränkter Freizügigkeit für Arbeitskräfte (vgl. Fischer und Straubhaar 1994). Abhängig von unterschiedlichen ökonomische Dynamiken in den nordischen Ländern kam es zum Beispiel zu signifikanten Wanderungsbewegungen der FinnInnen nach Schweden in den 1990er Jahren oder - wie gegenwärtig zu beobachten - der SchwedInnen und FinnInnen nach Norwegen. Im Laufe der 199oer Jahre und als Reaktion auf die Balkankriege bzw. auf die damit einhergehenden Flüchtlingsströme öffneten sich viele nordische Länder (allerdings in unterschiedlichem Ausmaße) für die Migration. Die nordischen Länder wurden somit ethnisch heterogene Gesellschaften. So ist der Anteil der im Ausland geborenen Menschen in Schweden im innernordischen Vergleich am höchsten (2013 $16 \%)$, gefolgt von Norwegen (13,9\%), Dänemark (8,5\%) sowie Finnland (5,6\%). Die klassischen Migrationsländer wie Luxemburg (43,7\%), Schweiz $(28,3 \%)$ oder

1 In diesem Beitrag wird der Begriff Skandinavien und nordische Länder synonym verwendet. Die nordeuropäische Staatenfamilie umfasst die fünf nordischen Nationalstaaten Dänemark, Finnland, Island, Norwegen und Schweden sowie die drei autonomen Regionen Grönland, Färöer Inseln und Åland. Da rechtspopulistische Parteien in Island bislang nicht in Erscheinung getreten sind, konzentriert sich dieser Beitrag auf die Entwicklungen in Dänemark, Finnland, Norwegen und Schweden. Vgl. allgemein zum Norden: in deutscher Sprache C. Förster et al. (2014), B. Henningsen et al. (2015) sowie S. Jochem (2012); in englischer Sprache D. Arter (2016) sowie Nedergaard und Wivel (2018). 
Australien $(27,7 \%)$ weisen deutlich höhere Werte auf. Deutschland nimmt mit $12,8 \%$ einen mittleren Rangplatz aller OECD Staaten ein. ${ }^{2}$

Die nordischen Demokratien waren lange Zeit Hochburgen der Arbeiterbewegung - jüngst können sie allerdings fast schon als Hochburgen rechtspopulistischer Parteien in Europa gedeutet werden. ${ }^{3}$ Zumindest haben die Wahlerfolge rechtspopulistischer Parteien in Dänemark und Norwegen seit den 199oer Jahren, in Finnland seit den 2oooer Jahren und in Schweden seit der jüngsten Vergangenheit dazu geführt, dass klassische rechtspopulistische Themen wie Migration und nationale Kultur auf die politische Agenda gelangten und den Parteienwettbewerb in den jeweiligen Ländern veränderten.

Die nordische Migrations- und Integrationspolitik wurde mitunter als offen und integrativ wahrgenommen, da die universalistischen Wohlfahrtsstaaten des Nordens große Anstrengungen zur Integration unternahmen. Spätestens mit Beginn der 200oer Jahre trifft zumindest für Dänemark diese Wahrnehmung nicht mehr zu. Die rechtspopulistische Dänische Volkspartei konnte als Unterstützungspartei bürgerlicher Minderheitsregierungen ihren Einfluss auf viele Bereiche der Migrations-, Integrations- und Sozialpolitik ausweiten. Immer stärker habe sich der universalistische Charakter dieser Politik abgeschwächt und ein Wohlfahrtschauvinismus sei verstärkt worden, bei dem die politischen Programme nach ethnischen Kriterien abgestuft würden (vgl. A.-H. Bay et al. 2013; J. G. Andersen 2007). Die Migrations- und Integrationspolitik wurde zur Achillesferse der nordischen Wohlfahrtsstaaten erklärt (vgl. Brochmann und Hagelund 2015; C. E. Schall 2016) - auch deshalb, da durch die Austeritätspolitik der nordischen Länder seit den nordischen Finanzkrisen der frühen 1990er Jahre die budgetären Freiräume durch strikte Budgetregeln deutlich eingeschränkt wurden (vgl. Haffert und Mehrtens 2013; P. Mehrtens 2014).

In diesem Beitrag werden die Dynamiken rechtspopulistischer Mobilisierung und Politikbeeinflussung in den nordischen Demokratien vor dem Hintergrund der außernordischen Immigration analysiert. Ich argumentiere, dass die Migrationspolitik im Norden in einen Kulturkampf mündete, bei dem die rechtspopulis-

2 Diese Daten basieren auf https://data.oecd.org/migration/foreign-born-population.htm (Zugriff: 20. 03. 2018).

3 Es ist fraglich, ob die Benennung dieser Parteienfamilie als populistisch den Kern der strategischen Gemeinsamkeiten dieser Parteien ausmacht. In Anlehnung an Jens Rydgren (2017) schlage ich vor, eher von radikal-nationalistischen Parteien zu sprechen. Allerdings verwende ich hier den Begriff des Rechtspopulismus, um die Homogenität dieses Bandes nicht zu stören. Vgl. zu dieser Thematik Jörke und Selk (2017), W. Müller (2016), die Beiträge in J. Rydgren (2018) sowie aus genuin nordischer Perspektive Jungar und Jupskås (2014), A.-C. Jungar (2017) sowie A. Widfeldt (2015a; 2018). 
tischen Parteien erfolgreich die Offenheit der nordischen Volksheime ${ }^{4}$ einschränken konnten. Ein Wohlfahrtschauvinismus und eine restriktive Migrationspolitik sind ebenso Anzeichen dieses rechtspopulistischen Erfolges wie eine zunehmende Europaskepsis im Norden. Eine weitere Ressource für rechtspopulistische Mobilisierung stellt die nordische Ausrichtung auf Minderheitsregierungen dar. Die Notwendigkeit zu Kompromissen in Regierungsverantwortung konnte rechtspopulistische Parteien aber nicht durchweg entzaubern. Die RechtspopulistInnen im Norden sind gekommen, um zu bleiben und zu regieren.

\section{Entstehung und Struktur rechtspopulistischer Parteien im Norden}

Seit den 1970er Jahren errangen rechtspopulistische Parteien im Norden nicht nur erstmals nationale Parlamentssitze, sondern beeinflussen seither durch ihre mediale Präsenz zudem weite Teile der politischen Öffentlichkeit und der politischen Agenda. Die älteste rechtspopulistische Partei ist die Finnische Landvolkpartei (eine Abspaltung der Zentrumspartei), die bereits im Jahr 1970 10,5\% der Stimmen bei nationalen Wahlen erreichte und von 1983 bis 1990 Mitglied in finnischen Regierungen war. Diese Regierungsverantwortung und innerparteiliche Querelen führten allerdings zum Niedergang der Partei sowie zu einer vernichtenden Wahlniederlage im Jahr 1995; noch im selben Jahr wurde vom Führungspersonal der Partei als Nachfolgepartei die Partei der Wahren Finnen gegründet (vgl. Tabelle 1). Während sich die Landvolkpartei nahezu ausschließlich für die Interessen der Landbevölkerung einsetzte, übernahmen die Wahren Finnen auch Themen der Migration, der europäischen Integration sowie der nationalen Kultur ${ }^{5}$ - wie es die neugegründeten RechtspopulistInnen in Dänemark und Norwegen bereits vorgemacht hatten. Finnland ist jedoch ein Beispiel für eine weitere konfliktbeladene Spaltung einer rechtspopulistischen Partei, bei der sich 2017 ein auf die Europa-Frage fokussierter sowie gemäßigter Teil um den Außen- und Europaminister Timo Soini von den Wahren Finnen abspaltete und die Partei Blaue Zukunft

4 Als Volksheim (folkhem) wird der schwedische und nordische Wohlfahrtsstaat mit seiner inklusiven Solidarität bezeichnet. Der Begriff wurde erstmals vom Vorsitzenden der schwedischen Sozialdemokratie, Per Albin Hansson, im Jahre 1928 geprägt. Grundlegend hierfür B. Henningsen (2013).

5 Die rechtspopulistische Thematisierung der nationalen Kultur in Finnland zielt unmittelbar auf die schwedischsprachige Minderheit im Land (und den Status der zu Finnland gehörigen autonomen Region Åland) ab; ca. fünf Prozent der finnischen Bevölkerung sprechen Schwedisch als ihre Muttersprache. Bisher gelang es den RechtspopulistInnen allerdings nicht, die offizielle Zweisprachigkeit des Landes zu beenden. 
Tabelle 1 Gründungen und Wahlerfolge rechtspopulistischer Parteien im Norden

\begin{tabular}{lllll}
\hline & $\begin{array}{l}\text { Dänemark } \\
\text { Danks Folke- } \\
\text { parti (DF) }\end{array}$ & $\begin{array}{l}\text { Finnland } \\
\text { Perussuo- } \\
\text { malaiset (PS) }\end{array}$ & $\begin{array}{l}\text { Norwegen } \\
\text { Fremskritts- } \\
\text { partiet (FrP) }\end{array}$ & $\begin{array}{l}\text { Schweden } \\
\text { Sverigedemo- } \\
\text { kraterna (SD) }\end{array}$ \\
\hline Gründung & $1972 / 1995$ & $1959 / 1995$ & 1973 & 1988 \\
$\begin{array}{l}\text { 1. Einzug ins } \\
\text { nationale Par- }\end{array}$ & $1973 / 1998$ & $1962 / 1995$ & 1973 & 2010 \\
$\begin{array}{l}\text { lament } \\
\text { Minimum/Jahr }\end{array}$ & $7,4 \% / 1998$ & $1,0 \% / 1999$ & $3,7 \% / 1985$ & $5,7 \% / 2010$ \\
Maximum/Jahr & $21,1 \% / 2015$ & $19,0 \% / 2011$ & $22,9 \% / 2009$ & $12,9 \% / 2014$ \\
$\begin{array}{l}\text { Aktuell/letzte } \\
\text { Wahl }\end{array}$ & $21,1 \% / 2015$ & $17,6 \% / 2015$ & $15,2 \% / 2017$ & $12,9 \% / 2014$ \\
\hline
\end{tabular}

Anmerkung: In Dänemark werden die Gründungsdaten sowie der erste Einzug ins nationale Parlament sowohl für die Fortschrittspartei als auch für die Dänische Volkspartei (DF) angegeben; die Angaben für die Wahlergebnisse beziehen sich nur auf die Dänische Volkspartei. Ebenso beziehen sich die finnischen Wahlergebnisse nur auf die Partei der Wahren Finnen, die Gründungsdaten hingegen auf die Landvolkpartei sowie auf die Partei der Wahren Finnen. Die schwedische Neue Demokratie (NyD) wird aufgrund ihrer sehr kurzen parlamentarischen Repräsentation (1991-1994) nicht in der Tabelle berücksichtigt.

Quelle: www.parties-and-elections.de; S. Jochem (2012, S. 101-106)

(Sininen tulevaisuus/SIN) gründete. Nunmehr prägt ein stark auf das Migrationsthema und den Kulturkampf ausgerichteter Teil um den neuen Vorsitzen Jussi Halla-aho die Partei der Wahren Finnen, ohne jedoch in der Regierung repräsentiert zu sein (da ausnahmslos alle Regierungsmitglieder der Wahren Finnen zur Blauen Zukunft gewechselt sind).

Der dänische Steuerrechtler Mogens Glistrup gründete die Fortschrittspartei (FrP) 1972 als Organisation, die seine Kritik am dänischen Steuer- und Wohlfahrtsstaat vorantreiben sollte. Unter seiner charismatischen Führerschaft entwickelte sich die FrP zur reinen Querulantin im Parteienwettbewerb und sie perfektionierte die parlamentarische Provokation als wichtigstes Zeichen ihrer politischen Arbeit. Die lose organisierte Partei büßte aber seit den 198oer Jahren stetig an parlamentarischer Macht ein. Pia Kjaersgaard bildete bereits vor dem endgültigen Ende der FrP 1995 die Dänische Volkspartei (DF). Sie setzte auf eine straffe Parteiorganisation, verminderte die Kritik an Steuer- und Sozialstaat und verstärkte vor allem die Thematisierung der Einwanderung, der kulturellen Identität und der EU-Kritik. Die Partei erreichte bei der Parlamentswahl 2001 genau $12 \%$ der Stimmen und wurde hinter der Liberalen Venstre zweitstärkste bürgerliche Partei. Mit diesem Wahlerfolg löste die Liberale Venstre den »cordon sani- 
taire « auf, und die DF wurde zur sehr einflussreichen Mehrheitsbeschafferin einer Minderheitskoalition aus Liberaler Venstre (V) und Konservativer Partei (KF) bis 2011. Nach einer sozialdemokratisch geführten Minderheitsregierung ist die DF seit 2015 erneut Mehrheitsbeschafferin für eine bürgerliche Koalition, die erneut von der Liberalen Venstre angeführt wird und noch die Liberale Allianz sowie die Konservative Partei umfasst.

»Anders Langes Partei für eine starke Rückführung der Steuern, Abgaben und öffentlichen Eingriffe « war das norwegische Pendant zur frühen dänischen Fortschrittspartei und gründete sich 1973. Der charismatische Führungsanspruch von Anders Lange sowie die Kritik am norwegischen Steuer- und Wohlfahrtsstaat waren bereits im Namen ausgeflaggt. Nach dem Tod des Parteigründers übernahm Carl I. Hagen 1974 die Parteiführung und benannte die Partei 1977 nach dänischem Vorbild in Fortschrittspartei ( $\mathrm{FrP}$ ) um. Hagen konnte nicht nur die Parteiorganisation festigen, er leitete auch den thematischen Schwenk weg von Themen des Steuer- und Wohlfahrtsstaates, hin zu den Themen Migration, der EU sowie kulturelle Identität ein - woraufhin sich allerdings ein proeuropäischer und libertärer Flügel von der Partei abspaltete. Seit den 199oer Jahren konnte die Partei ihre Erfolge an den Wahlurnen ausbauen. 2013 wurde die FrP unter Führung von Siv Jensen Mitglied einer bürgerlichen Minderheitskoalition, die von der Konservativen Partei unter Erna Solberg angeführt wird. Nach der Wiederwahl der Koalitionsparteien in der Reichstagswahl 2017 trat noch die Liberale Venstre dieser Koalition bei; die Koalition ist jedoch weiterhin auf die parlamentarische Unterstützung der Christdemokraten angewiesen (vgl. S. Jochem 2018).

Eine Ausnahme dieser rechtspopulistischen Erfolge im Norden stellte lange Zeit Schweden dar. Der erste parlamentarische Durchbruch gelang der rechtspopulistischen Neuen Demokratie (NyD) 1991, allerdings scheiterte die von inneren Machtkämpfen zerrissene Partei bereits in der nächsten Reichtstagswahl 1994. Die Schwedendemokraten (SD) gründeten sich zwar bereits 1988, ihr parlamentarischer Durchbruch erfolgte allerdings erst sehr spät; die Partei, die in der Öffentlichkeit immer wegen ihrer Nähe zu rechtsextremen Bewegungen kritisiert wurde, konnte erst 2010 mit 5,7\% der Stimmen in den Reichstag einziehen. Bei der nächsten Wahl stieg der Rückhalt in der Wahlbevölkerung zwar auf 12,9\% an, aber alle Parteien verweigern (bislang) eine systematische Zusammenarbeit mit dieser Partei. Der in Schweden seit langem praktizierte Blockwettbewerb des Parteiensystems führt mit dieser Form des »cordon sanitaire « zu großen Problem in der Regierungspolitik, da die SD sich mitunter als Zünglein an der Waage zwischen den Blöcken profilieren kann. 


\section{Programmatik rechtspopulistischer Parteien im Norden}

Das programmatische Profil der vier rechtspopulistischen Parteien im Norden näherte sich im Verlauf der Zeit durchaus an (vgl. A.-C. Jungar 2017), gleichwohl bestehen noch deutliche Differenzen (vgl. Abbildung 1). Die norwegische Fortschrittspartei ist ihrem libertären Gründungspathos noch am stärksten verhaftet geblieben. Zumindest zeigen die Daten des Chapel Hill Survey im Jahr 2014, dass sie deutlich klarer als ihre Schwesternparteien auf dem libertären Pol der ökonomischen Arbeitsverschränkung von Markt und Staat eingestuft wird. Zweitens ist die norwegische FrP beim Thema nationaler Kultur, Tradition und Stabilität nicht so eindeutig am autoritären Pol angesiedelt, wie dies für die finnische PS, die dänische DF oder die schwedische SD ausgewiesen wird. Zudem werden diese drei Parteien in ökonomischer Hinsicht als Mitteparteien ausgewiesen. In ökonomischen Fragen liegen diese drei Parteien nach Einschätzung der Experten näher bei den Positionen der jeweiligen Sozialdemokraten in Dänemark (S), Finnland (SDP) und Schweden (SAP) als die norwegische FrP oder die konservativen Parteien in Dänemark (KF), Finnland (KOK) und Schweden (M). Nach diesen Einschätzungen grenzt sich die norwegische FrP also eindeutig von ihren nordischen Schwesterparteien ab.

Neben Tradition und Autorität fokussieren die vier rechtspopulistischen Parteien des Nordens vor allem die Migrationsfrage. Seit den thematischen Neuausrichtungen in den 1990er Jahren werden in unterschiedlichsten Wahlplattformen und in der Kommunikation mit der Öffentlichkeit die Probleme der Migration thematisiert. Insbesondere in Dänemark schaffte es die DF, das Thema Migration bei nahezu allen Parteien zu einem Thema der Wahlplattformen zu machen stärker, als dies in anderen Ländern Europas zu beobachten ist (vgl. Green-Pedersen und Otjes 2017). Gleichwohl ist dieser Fokus auf Migrationsprobleme und die Verteidigung einer nationalen Kultur nicht in allen vier Parteien gleich stark ausgeprägt. Zumindest in Hinsicht auf die offizielle Kommunikation der Partei ist die norwegische FrP bis auf den heutigen Tag und war die finnische PS bis zur Spaltung 2017 diesbezüglich eher zurückhaltend. »All four (rechtspopulistische Parteien des Nordens, $S J$ ) meet the three populist radical right criteria of nativism, authoritianism, and populism, although immigration is given higher priority in DF and SD than in FrP and PS « (A. Widfeldt 2018, S. 552).

Die rechtspopulistischen Parteien Dänemarks (DF) sowie Norwegens (FrP) können auf die längste Geschichte und die wenigsten Zäsuren verweisen. Die finnischen RechtspopulistInnen (PS) weisen zwar ein ähnliches Alter in der Parteiengeschichte auf, allerdings sind dort die organisatorischen Zäsuren beachtlich. In Schweden hingegen konnten sich die RechtspopulistInnen bislang nur schwach 
Abbildung 1 Programmatisches Profil der RechtspopulistInnen in Nordeuropa, 2014

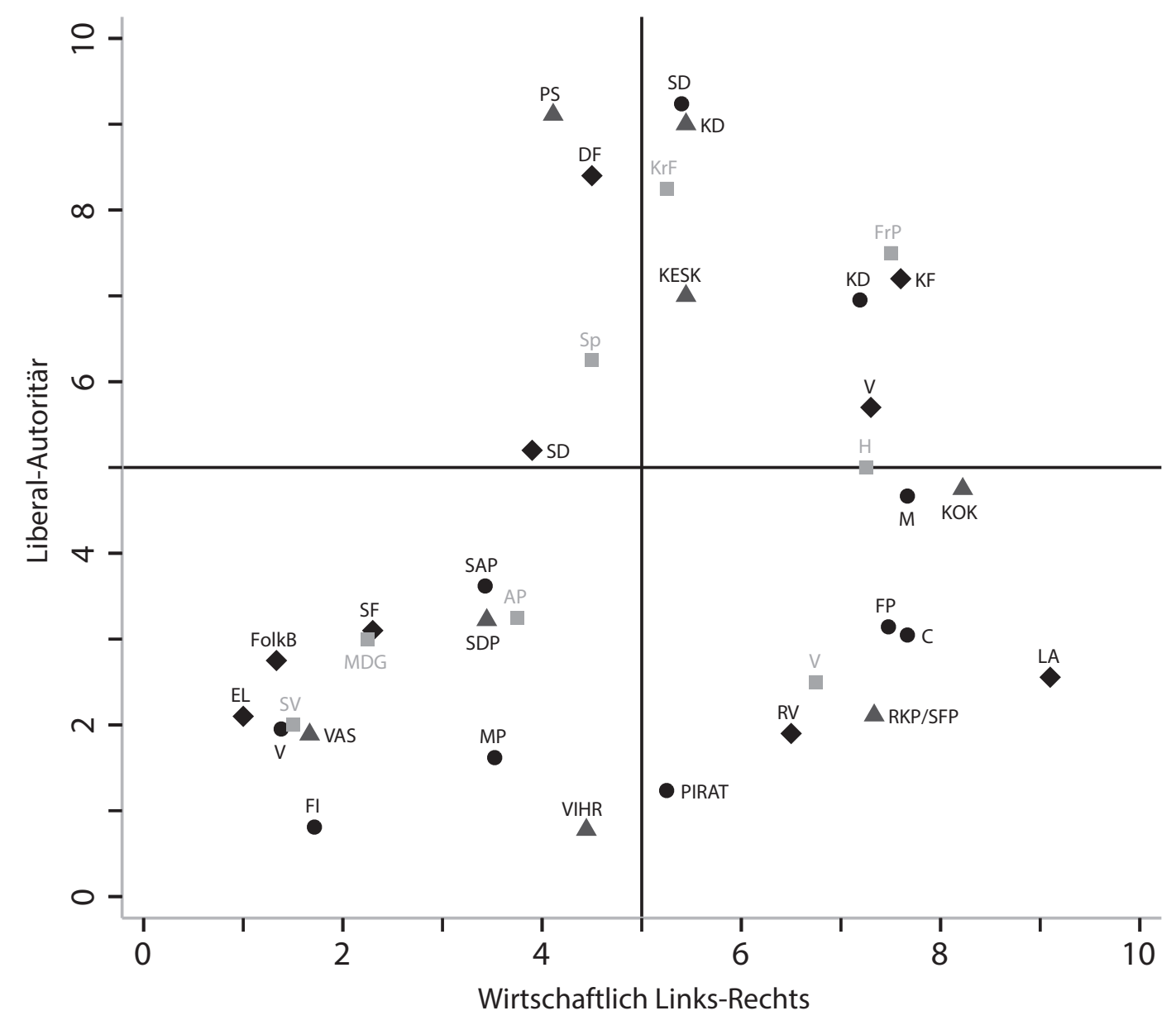

$$
\begin{array}{ll}
\text { - Schweden } & \forall \text { Dänemark } \\
\Delta \text { Finnland } & \square \text { Norwegen }
\end{array}
$$

Anmerkung: Daten des Chapel Hill Expert Surveys aus dem Jahr 2014. Während in der ökonomischen Dimension klassische Fragen der Arbeitsverschränkung von Markt und Staat abgefragt werden, beziehen sich die Fragen für die liberal-autoritäre Achse vor allem auf kulturelle Fragen der Selbstbestimmung oder der Einschätzung von Tradition, Ordnung und Stabilität. Die Einstufung der Positionen basiert für Dänemark auf 11 ExpertInnenmeinungen, für Finnland auf 10, für Schweden auf 22 und für Norwegen auf lediglich 4.

Quelle: Chapel Hill Expert Survey, 2014 (https://www.chesdata.eu/our-surveys) 
im Parteienwettbewerb behaupten. In jüngster Vergangenheit scheint es jedoch so zu sein, dass die Schwedendemokraten (SD) sowohl auf nationaler Ebene als auch auf kommunaler und regionaler Ebene erfolgreich Fuß fassen können.

\section{Anhänger- und Wählerschaft}

Die RechtspopulistInnen des Nordens sind zwar gegenwärtig erfolgreich, aber sie sind dies in einem unterschiedlichen Ausmaße - und sie sind dabei nicht vor Rückschlägen gefeit. Die größten Wahlerfolge sind vor allem in Dänemark und Norwegen zu beobachten (vgl. Abbildung 2). In Finnland konnte die PS erst 2011 ihre bis dahin eher schlechten Wahlresultate verbessern - und dann bereits 2015 in die Regierungsverantwortung gelangen. In Schweden hingegen ist die Geschich-

Abbildung 2 Sitzanteile rechtspopulistischer Parteien in Nordeuropa, 1990-2017

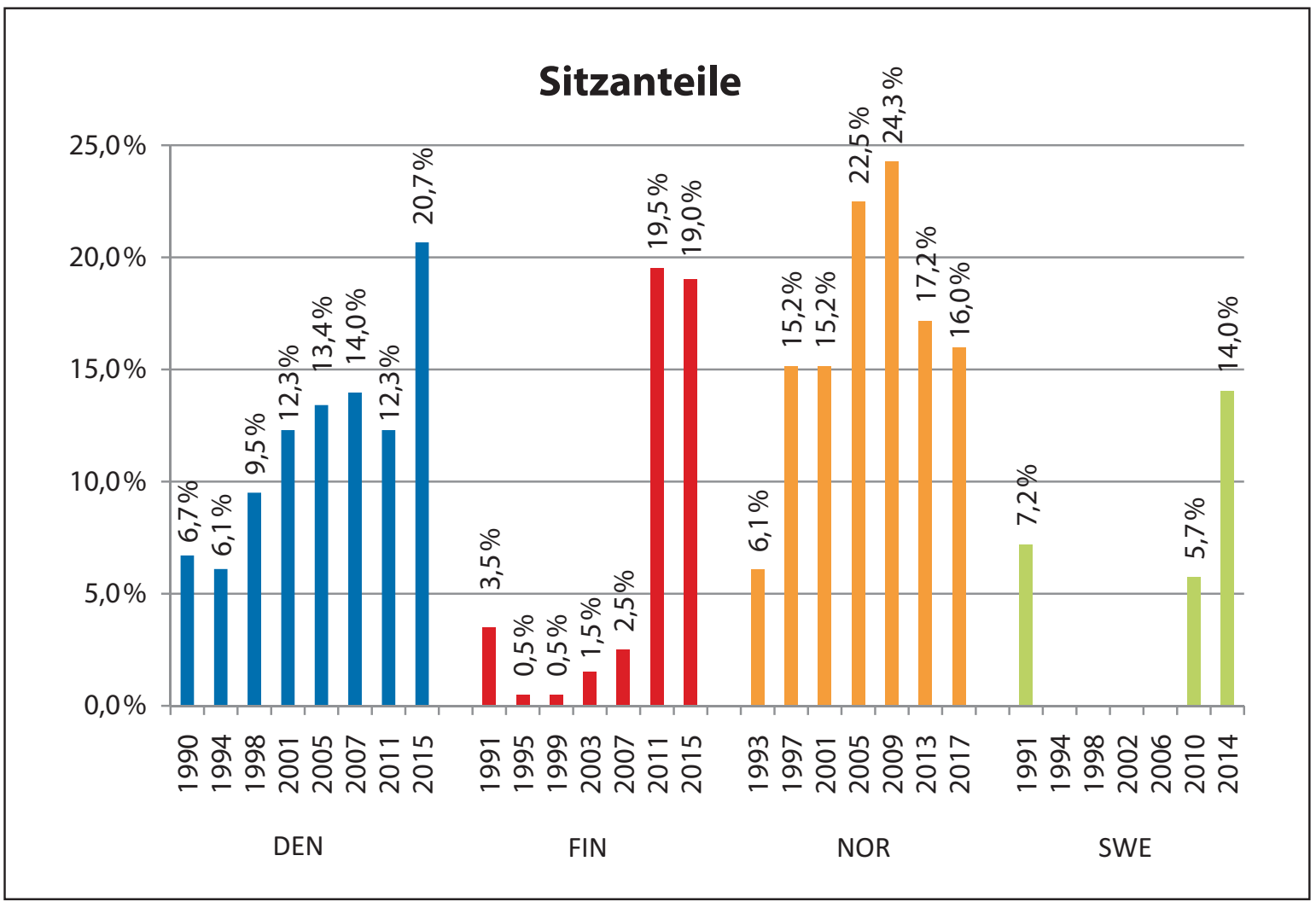

Anmerkung: Es werden die prozentualen Sitzanteile für radikal-nationalistische Parteien in den nationalen Parlamenten aufgeführt. In Dänemark spiegeln 1998 sowie 2001 die Daten für die dänische Fortschrittspartei und die Dänische Volkspartei wider; danach beziehen sich die Werte nur auf die Dänische Volkspartei. In Schweden spiegeln die Werte in 1991 die Ergebnisse für Ny Demokrati wider, danach die Werte für die Schwedendemokraten.

Quelle: Zusammenstellung und Berechnung auf der Basis von www.parties-and-elections.eu 
te rechtspopulistischer Mobilisierungen von Zäsuren und Unterbrechungen gekennzeichnet. Die 1991 gegründete Ny Demokrati konnte einen Achtungserfolg verbuchen, allerdings führten innerparteiliche Auseinandersetzungen zum Zerfall der Partei und zu ihrem Ausscheiden aus dem Reichstag im Jahr 1994. Die radikalen Nationalisten der Schwedendemokraten konnten erst 2010 erstmals in den Reichstag einziehen. Mit 14\% der Parlamentssitze erzielten sie bei der nationalen Wahl 2014 einen großen Erfolg, der sie in die Nähe der Wahlergebnisse der Dänischen Volkspartei bzw. der norwegischen Fortschrittspartei brachte.

Die Erklärung der unterschiedlichen Wahlerfolge kann auf Dynamiken des Parteienwettbewerbs und Einflüsse des Wahlrechts einerseits (Angebot) sowie gesellschaftliche Mobilisierungsdynamiken und gesellschaftliche Problemwahrnehmungen andererseits (Nachfrage) zurückgeführt werden. ${ }^{6}$ Während sich in Dänemark, Finnland und Norwegen die Parteienlandschaft seit den 1970er Jahren zusehends ausdifferenzierte, verblieb Schweden noch sehr lange dem klassischnordischen Fünf-Parteien-System verhaftet. In Schweden konnten die Sozialdemokraten - aber auch die bürgerlichen Parteien - lange erfolgreich das Abwandern enttäuschter WählerInnen verhindern. Da in Dänemark, Finnland und Norwegen die Parteiensysteme sich seit den 1970er Jahre rasch diversifizierten und durch das Wahlrecht keine (hohen) Hürden für kleine Parteien existieren, konnten rechtspopulistische Bewegungen sich erfolgreich auf dem Wählermarkt durchsetzen. Zudem wurden von den bürgerlichen Parteien rasch Kooperationen mit den rechtspopulistischen Parteien eingegangen, sodass rechtspopulistische Themen und Interpretationen sich stark in der Öffentlichkeit durchsetzen konnten. Dass dann aber auch in Schweden die SD sich parlamentarisch durchsetzen konnte, hat nicht nur mit Veränderungen der gesellschaftlichen Problemwahrnehmungen zu tun. Der parlamentarische Durchbruch der SD erfolgte just zu dem Zeitpunkt, als sowohl die Sozialdemokratie Schwedens (SAP) als auch die bürgerliche Allianz - vor allem die Konservative Partei Schwedens (M) - zur Mitte schwenkten (vgl. Rydgren und van der Meiden 2016; A. Widfeldt 2015b).

Auf der Nachfrageseite können als förderliche Faktoren für den zunehmenden Wahlerfolg der RechtspopulistInnen im Norden die zunehmende Migration, die gesellschaftlich umstrittene europäische Integration sowie die auch im Norden stattfindende Austeritätspolitik gelten - bei der die unteren Einkommensschichte stagnieren und sich die Schere der materiellen Gleichheit bei Einkommen sowie Vermögen rasch weitet (vgl. P. Mehrtens 2014; J. Kvist et al. 2012). Die Wähler rechtspopulistischer Parteien werden oft als klassische Modernisierungsverlierer umschrieben (vgl. H.-G. Betz 1993), was sich als Stereotyp in der medialen Auseinandersetzung widerspiegelt. Der klassische Wähler rechtspopulistischer Par-

6 Für eine Übersicht vgl. H. Kitschelt (2018) sowie A. Widfeldt (2015a; 2018). 
teien sei demnach ein junger Arbeiter im privaten Sektor ohne höheren Bildungsabschluss und in einer materiell prekären Situation, der sowohl Migration als auch die politische (und gesellschaftliche) Elite mit ihrem kosmopolitischen Lebensstil ablehne.

Anders Widfeldt (2018) hat jüngst dieses Stereotyp einer Analyse auf der Grundlage von Daten des European Social Survey (2014/15) unterzogen und dabei widersprüchliche Ergebnisse zutage gefördert. Für die vier nordischen Länder kann als einzige Gemeinsamkeit gezeigt werden, dass die Ablehnung der Migration in allen vier Ländern statistisch signifikant die Wahlentscheidung erklären kann. Dies ist jedoch der einzige Faktor, der in allen vier Ländern statistisch signifikant ist. Denn die Fragen nach dem Geschlecht, nach dem Einkommen, nach dem Wirtschaftssektor oder die Einstellung gegenüber sexuellen Selbstbestimmungszielen weisen keine statistische Signifikanz auf. Die Wahlentscheidung für die dänische DF wird vor allem von Menschen getroffen, die keinen höheren Bildungsabschluss vorweisen können und - als einzigem Land im Norden - die politische Elite ablehnen. In Schweden ist vor allem die Ablehnung der Migration entscheidend, aber das Misstrauen in die Politik ist statistisch nur schwach signifikant. Die Ablehnung der EU ist nicht signifikant in Schweden, jedoch sehr deutlich ausgeprägt in Finnland. Nur in Finnland ist der Gender-Aspekt signifikant, nach dem vor allem Männer die PS wählen; zudem wird nur in Finnland die PS vor allem von älteren Personen gewählt. Dem oben skizzierten Stereotyp des rechtspopulistischen Wählers entspricht am ehesten Norwegen. Dort wird Arbeitslosigkeit, geringes Sozialkapital, Beschäftigung im privaten Sektor und die Ablehnung von Umverteilungspolitiken statistisch signifikant. Am stärksten wirken nach diesen statistischen Analysen in Norwegen das Alter und - wie in den anderen Ländern die Ablehnung von Migration (vgl. A. Widfeldt 2018, S. 553-557).

\section{Potenziale, Restriktionen und wohlfahrtsstaatliche Migrationspolitik im Norden}

Die nordischen RechtspopulistInnen sind nicht nur gekommen, um in den Parlamenten zu bleiben - sie bleiben dort auch, um zu regieren. Neben der indirekten Regierungsbeteiligung der DF in Dänemark von 2001 bis 2011 sowie seit 2015 konnten jüngst in Norwegen (seit 2013) sowie Finnland (seit 2015) rechtspopulistische Parteien Regierungsverantwortung übernehmen. Lediglich in Schweden ist die SD immer noch in einen »cordon sanitaire « eingehegt, wenngleich seitens der Konservativen Partei erste Annäherungen stattfanden (vgl. Tabelle 2). 
Tabelle 2 Etappen rechtspopulistischer Mobilisierung im Norden

\begin{tabular}{|c|c|c|c|}
\hline Dänemark & Finnland & Norwegen & Schweden \\
\hline \multirow{5}{*}{$\begin{array}{l}\text { 1990er Jahre: } \\
\text { Kein »cordon } \\
\text { sanitaire«, erste } \\
\text { Kooperationen, } \\
\text { indirekte Wirkung auf } \\
\text { Parteienwettbewerb }\end{array}$} & 1990er Jahre & 1990er Jahre & Seit 1990 \\
\hline & $\begin{array}{l}\text { Kein »cordon } \\
\text { sanitaire» }\end{array}$ & Kein »cordon sanitaire» & $\begin{array}{l}\text { »Cordon Sanitaire« für } \\
\text { NyD sowie SD }\end{array}$ \\
\hline & & 1997-98 & \\
\hline & Seit 2009 (EP-Wahl) & FrP als Unterstützerin & $2006-2010$ \\
\hline & Erste Kooperationen & $\begin{array}{l}\text { der Mitte-Rechts-Min- } \\
\text { derheitskoalition }\end{array}$ & $\begin{array}{l}\text { Mehrheitskoalition der } \\
\text { Allianz für Schweden, SD }\end{array}$ \\
\hline \multirow{3}{*}{$\begin{array}{l}2001-2011 \\
\text { DF unterstützt Mitte- } \\
\text { Rechts-Minderheits- } \\
\text { regierungen }\end{array}$} & $\begin{array}{l}2011 \text { Koalitionsver- } \\
\text { handlungen }\end{array}$ & (Bondevik I) & nicht im Reichstag \\
\hline & & $2001-2005$ & $2010-2014$ \\
\hline & $\begin{array}{l}\text { Seit } 2015 \\
\text { Regierungspartei und } \\
\text { Regierungskrise }\end{array}$ & $\begin{array}{l}\text { FrP als Unterstützerin } \\
\text { der Mitte-Rechts-Min- } \\
\text { derheitskoalition } \\
\text { (Bondevik II) }\end{array}$ & $\begin{array}{l}\text { Minderheitskoalition der } \\
\text { Allianz, SD Zünglein an } \\
\text { der Waage }\end{array}$ \\
\hline \multirow{4}{*}{$\begin{array}{l}\text { Seit } 2015 \\
\text { DF unterstützt Mitte- } \\
\text { Rechts-Minderheits- } \\
\text { regierung }\end{array}$} & 2017 & & Seit 2014 \\
\hline & $\begin{array}{l}\text { Partei gespalten: } \\
\text { PS \& SIN }\end{array}$ & $\begin{array}{l}\text { Seit } 2013 \\
\text { Minderheitskoalition } \\
\text { zusammen mit Høyre } \\
\text { (Rechte) (Unterstützung } \\
\text { durch Christliche Volks- } \\
\text { partei/KrF und Venstre), }\end{array}$ & $\begin{array}{l}\text { Rot-Grüne Minder- } \\
\text { heitskoalition, Re- } \\
\text { gierungskrise, Dezem- } \\
\text { berübereinkommen } \\
\text { (gescheitert 2015) }\end{array}$ \\
\hline & & Wiederwahl 2017 und & Seit 2017 \\
\hline & & $\begin{array}{l}\text { Ausweitung der Re- } \\
\text { gierung durch Venstre }\end{array}$ & $\begin{array}{l}\text { Annäherung der } M \text { an } \\
\text { die SD }\end{array}$ \\
\hline
\end{tabular}

Quelle: A.-C. Jungar (2017); A. Widtfeld (2015a; 2018); S. Jochem (2012; 2018)

\section{Dänemark}

Den größten Einfluss auf die nationale Regierungspolitik konnte die DF ausüben. Als Unterstützungspartei für die von der Liberalen Venstre geführten Minderheitsregierungen hat sie sich nach der äußerst polarisierten Parlamentswahl von 2001 (die nur neun Tage nach dem Terrorakt in New York vom 11. September 2001 stattfand) rasch als vertrauensvolle und vor allem verlässliche Unterstützungspartei profiliert. Bereits 2002 kam es durch einen Kompromiss zwischen der Regierung und der DF zu einer der stärksten Einschränkungen im dänischen Migrationsrecht seit 1983 (vgl. F. J. Christiansen 2017, S. 66). Dieser restriktive Kurs in der Migrationspolitik wurde weitgehend beibehalten bis zur Wahl von 2011. ${ }^{7}$

7 Dänemark kam auch in kulturellen Streitfragen im weitesten Sinne in den Fokus der globalen Öffentlichkeit. So vor allem im Zusammenhang mit dem Karikaturenstreit (2005) oder im Zusammenhang mit den Attentaten in Kopenhagen vom 14. 02. 2015. 
Der dänische Parteienwettbewerb im linken Lager wandelt sich seit 2009 kurzfristig. Die Sozialdemokratie löste ihre feste Zusammenarbeit mit der liberalen (mitunter libertären) RV 2009 auf. Während die SD eine kritischere Position in der Migrationspolitik einnahm, forcierte die RV weiterhin eine uneingeschränkte Einwanderungspolitik. Die SozialdemokratInnen suchten in der Sozialistischen Volkspartei (SF) eine Unterstützerin, während die RV bei den einschränkenden Reformen im Bereich der Frühverrentung die Minderheitsregierung unterstützte. Zwar konnte die RV bei der Wahl 2011 an Rückhalt zulegen, aber es gelang den Sozialdemokraten zusammen mit der SF und der RV eine Minderheitsregierung zu bilden, unterstützt von zwei kleineren liberalen Parteien. Mit dieser Koalitionslogik wurden die Reformen im Bereich der Frühverrentung nicht angetastet; allerdings sollten die strikten Migrationsgesetze gelockert werden. Folgerichtig kam es $2012 \mathrm{zu}$ Reformen, die die strikten Migrationsregeln auflockern sollten; allerdings kann deren Wirkung als eher moderat eingestuft werden (vgl. F. J. Christiansen 2017, S. 63).

Die Migrationspolitik blieb neben Fragen der ökonomischen Leistungskraft zentrales Thema bei der Wahl 2015. Obwohl Sozialdemokraten und RV vor der Wahl eine weitere Zusammenarbeit vereinbart hatten, konnten die vier bürgerlichen Parteien vor der Wahl ebenfalls eine gemeinsame Plattform verabschieden, in der eine Einschränkung der Migrationspolitik und eine Rücknahme der liberalen Reformen eingefordert wurden. Damit errangen die bürgerlichen Parteien im Parlament eine knappe Mehrheit gegenüber dem linken Lager. Zudem konnte sich die DF 2015 als stärkste Partei im bürgerlichen Lager profilieren. Trotzdem lehnte die DF eine direkte Regierungsbeteiligung ab, obwohl diese Position nur von $49 \%$ der ParteianhängerInnen unterstützt wurde (vgl. A.-C. Jungar 2017, S. 80). Der Vorsitzende der DF, Kristian Thulesen Dahl, äußerte darauf Verständnis für die Forderungen an die Parteiführung, einer bürgerlichen Koalition offiziell beizutreten. Er führte aber auch aus, "man kann nicht automatisch sagen, dass der Einfluss in der Regierung größer ist als in der Opposition " (A.-C. Jungar 2017, S. 81; Übersetzung $S J) .^{8}$

Die einschränkenden Maßnahmen in der dänischen Migrationspolitik wurden vor dem Hintergrund der Flüchtlingskrise in Europa in einer Sondersitzung unmittelbar nach der Regierungsbildung im Sommer 2015 verabschiedet. In der Öffentlichkeit vor allem in Erinnerung geblieben ist die Regelung, Flüchtlingen an der Grenze Wertgegenstände zu konfiszieren, um so deren Aufenthalt zu finanzieren. Die Restriktionen wurden seither weiter vorangetrieben. Die Integra-

8 Übersetzung des Autors: »Men, man kann inte automatiskt säga att inflytandet är större i regeringsställning än i oppositionen. « 
tionsministerin Inger Støjberg (Venstre) - die als resolute Befürworterin einer einschränkenden Migrationspolitik gilt - präsentierte auf der Homepage ihres Ministeriums eine Zählung, mit der die Einschränkungen in der Migrations- und Flüchtlingspolitik seit Regierungsantritt aufgeführt werden. Zum Stand Ende April 2018 werden 73 einschränkende Maßnahmen seit Beginn der Legislaturperiode 2015 aufgelistet. ${ }^{9}$

Im Zusammenhang mit der Flüchtlingskrise 2015 entschied sich die bürgerliche Minderheitsregierung dafür, die Flüchtlinge ohne Kontrolle und Registrierung nach Schweden weiterreisen zu lassen. Dies führte zu Beginn des Jahres 2016 dazu, dass Schweden Passkontrollen an der dänisch-schwedischen Grenze - erstmals seit den 1950er Jahren - einführte. Die dänische Regierung führte daraufhin stichprobenartige Grenzkontrollen an der dänisch-deutschen Grenze ein, die kritische Reaktionen in der deutschen sowie europäischen Politik auslösten. Dies war ein Schritt, der allerdings kurz zuvor bereits von der norwegischen und der finnischen Regierung durchgeführt worden war (vgl. T. Etzold 2016, S. 2). Die innernordische Freizügigkeit ist seit ihrer Einführung in den $1950 e r$ Jahren damit weitgehend ausgehebelt.

\section{Norwegen}

Die norwegische FrP entschied sich - anders als die DF - zur offiziellen Regierungsbeteiligung und trat 2013 in eine bürgerliche Minderheitskoalition unter Führung der Konservativen Partei ein. Gestützt wurde die Minderheitsregierung von den Christdemokraten und der Liberalen Venstre. Die FrP konnte wichtige Ministerien übernehmen; die Parteivorsitzende Siv Jensen übernahm zum Beispiel das Finanzministerium. Nach einer Kabinettsumbildung im Dezember 2015 übernahm zudem Sylvi Listhaug das Ministerium für Immigration und Integration. Unmittelbar nach Regierungsantritt konnte die FrP noch einen Erfolg mit der Verschärfung der Migrationspolitik erreichen. In anderen Bereichen wurden der FrP rasch von den Unterstützungsparteien (und der faktischen Opposition) Grenzen gesetzt. Viele von den Zielen, die in der Parteirhetorik als bedeutsam präsentiert wurden, konnte die Partei nicht umsetzen, zum Beispiel die Liberalisierung des Alkoholverkaufs sowie die Liberalisierung von Glücksspielen (vgl. S. Jochem 2018). Vor diesem Hintergrund erreichte die FrP bei den Kommunalwahlen 2015 nur noch zehn Prozent der Stimmen; das Ende der bürgerlichen Min-

9 Vgl. die Homepage des Ministeriums http://uim.dk/ sowie die Auflistung der einzelnen Maßnahmen unter http://uim.dk/gennemforte-stramninger-pa-udlaendingeomradet (letzter Zugriff: 7. 05. 2018). 
derheitskoalition und einer Regierungsbeteiligung der FrP erschien nur noch eine Frage der Zeit.

Die Ölpreiskrise Norwegens eröffnete allerdings eine erste Profilierungsmöglichkeit der FrP in der Regierung. Die Finanzministerin Siv Jensen (FrP) setzte sich gegen den Widerstand der Konservativen Partei durch und leitete mehr Kapital aus dem norwegischen Erdölfonds in den Haushalt der Regierung um, als nach den offiziellen Regeln vorgesehen ist. Dies erlaubte der eigentlich in ökonomischen Fragen libertär auftretenden Finanzministerin eine fulminante keynesiansische Politik, in deren Verlauf sie stark in die öffentliche Infrastruktur und den norwegischen Wohlfahrtsstaat investierte. Seit 2016 hellten sich die Zukunftserwartungen der norwegischen Bevölkerung auf, die Umfragewerte der FrP stiegen an und die der Arbeiterpartei - bis dahin mit bis zu $40 \%$ unangefochten stärkste Partei in den Umfragen - sanken deutlich ab.

Zum anderen profilierte sich die FrP in der Flüchtlingskrise. Die seit Dezember $2015 \mathrm{im}$ Amt befindliche Migrationsministerin Sylvi Listhaug (FrP) formulierte das Ziel, das restriktivste Flüchtlings- und Migrationsregime in Europa zu errichten. Als dann zusätzlich Flüchtlinge den beschwerlichen Weg über Russland nach Norwegen nahmen, forcierte die Migrationsministerin ihre Reformaktivitiäten. Sie legte ohne vorherige Verhandlung mit den Unterstützungsparteien dem Parlament ein Reformpaket vor, in dem deutliche Verschärfungen des Migrationsrechts enthalten waren. Allerdings scheiterte die Regierung bei vielen einzelnen Reformen an den Christdemokraten und an der Liberalen Venstre. Im Juli 2016 erfolgte im zweiten Anlauf der Versuch, die wohlfahrtsstaatlichen Leistungen für MigrantInnen zu reduzieren - ähnlich wie es in Dänemark zu beobachten ist (Wohlfahrtschauvinismus). Zwar befürwortete die Mehrheit der norwegischen Bevölkerung eine solche Dualisierung (vgl. A.-H. Bay et al. 2013), die Regierung scheiterte jedoch am Widerstand der Oppositionsparteien und vor allem am Widerstand der beiden Unterstützungsparteien. Trotzdem konnte die FrP zeigen, dass sie erfolgreich Regierungsgeschäfte führen kann (wie im Bereich der keynesianischen Fiskalpolitik zu beobachten war), gleichzeitig vehement für eine Verschärfung der Migrationspolitik einzustehen und auch bei Niederlagen nicht von diesem Ziel abzurücken. Mit der öffentlichen Verteidigung ihrer Position und ihrer antreibenden Rolle in der Regierung gelang es der FrP, die Schuld für die gescheiterten Reformen den Unterstützungsparteien zuzuschreiben.

Der Wahlkampf 2017 wurde vor allem vom Thema Migration und Flüchtlinge geprägt. Bereits früh zeichnete sich ein Sieg der bürgerlichen Minderheitskoalition ab. Vor allem die Arbeiterpartei vermochte ihren Niedergang in den Umfragen nicht umkehren. Die kleinen Unterstützungsparteien hingegen konnten letztlich von einer Besonderheit des norwegischen Wahlsystems profitierten: Sie bekamen knapp über vier Prozent der Stimmen und gelangten dadurch in den 
Genuss von Ausgleichsmandaten. Die Opposition errang 2017 folglich landesweit mehr Stimmen als das bürgerliche Regierungslager, allerdings konnte sich das bürgerliche Lager die Mehrheit an Mandaten dank der Ausgleichsmandate knapp sichern (vgl. S. Jochem 2018).

Die Minderheitsregierung unter der konservativen Ministerpräsidenten Erna Solberg wurde - ein Novum seit 1983 - nicht beendet, sondern um die Liberale Venstre erweitert. ${ }^{10}$ Nach langwierigen Sondierungsgesprächen einigten sich die drei Parteien am 16. Januar 2018 auf die Bildung einer erneuten Minderheitsregierung (Jeløya-plattform). ${ }^{11}$ Die Christdemokraten konnten sich nicht zu einer Regierungsbeteiligung durchringen, kündigten allerdings eine Unterstützung an, die diese Partei zum Zünglein an der Waage macht im Lager-Wettbewerb des norwegischen Parteiensystems. Die ehemalige - in der Öffentlichkeit polarisierend auftretende - Integrations- und Migrationsministerin Sylvi Listhaug wurde Justizministerien. Sie trat jedoch aufgrund eines Facebook-Postings bereits am 20.03. 2018 zurück: Sie hatte der Arbeiterpartei vorgeworfen, sie kümmere sich mehr um die Rechte von Terroristen als um die nationale Sicherheit. Dies führte $\mathrm{zu}$ einer Welle der Kritik seitens der Opposition und vor allem der Arbeiterpartei, immer noch die stärkste Fraktion im norwegischen Parlament. Während die Ministerpräsidentin Erna Solberg an der Ministerin festhalten wollte und den Misstrauensantrag auf die gesamte Regierung aussweitete, kündigten die Christdemokraten am Tag vor der Vertrauensabstimmung an, mit der Opposition und gegen die Regierung abzustimmen. Daraufhin trat die Justizministerin am Morgen der Abstimmung offiziell zurück, um damit eine Regierungskrise abzuwenden.

\section{Finnland}

Die finnischen RechtspopulistInnen, die Wahren Finnen (Perussuomalaiset/PS), traten erst 2015 einer Regierung bei. Ihre Mobilisierung verlief zögerlich, erst die Wahl von 2011 brachte die Partei in die Nähe einer möglichen Regierungsbeteiligung. Bereits bei dieser Wahl offenbarte sich die intern gespaltene Situation in der Partei. Während der Parteivorsitzende Timo Soini sich als kooperationsge-

10 Erstmals seit 1983 wurde vom in der Verfassung eingeräumten Recht Gebrauch gemacht, nach einer Wahl die Regierung nicht neu bestätigen zu lassen, sondern sie mit einer Partei zu ergänzen. Aus diesem Grund ist in offiziellen Dokumenten die Regierung Solberg I weiterhin seit $2013 \mathrm{im} \mathrm{Amt.} \mathrm{Auch} \mathrm{dies} \mathrm{ist} \mathrm{eine} \mathrm{institutionelle} \mathrm{Besonderheit} \mathrm{des} \mathrm{Regierens} \mathrm{im} \mathrm{par-}$ lamentarischen System Norwegens.

11 Der Text des Koalitionsvertrages ist auf der Website der norwegischen Regierung in norwegischer Sprache abrufbar: https://www.regjeringen.no/contentassets/e 4 c 3 cfd 7 e $4 \mathrm{~d} 4458 \mathrm{fa}_{8} 8 \mathrm{~d}_{3}$ d2bbie43bcbb/plattform.pdf 
neigter Politiker im Parlament darstellte und vor allem an der europäischen Integration (und der europäischen Krisenpolitik im Zusammenhang mit der Finanzkrise) Kritik übte, gelang einem Blogger mit Anti-Migrations- und AntiIslam-Themen, Jussi Halla-aho, ein Achtungserfolg für die PS in seinem Wahlkreis in Helsinki. Insofern zeigte sich schon bei der Wahl 2011, dass es eine »Partei innerhalb der Partei « bei den Wahren Finnen gab, die weniger Europa auf der Agenda hatte, sondern wie die DF Migration und Kultur zum zentralen Thema erheben wollte (vgl. Kuisma und Nygård 2017, S. 74 f.). Letztlich scheiterte die Regierungsbeteiligung der PS nach sehr langen Koalitionsverhandlungen an den Forderungen der PS, Finnland solle die Krisenpolitik der EU gegenüber den südeuropäischen Ländern (vor allem Griechenland) unmittelbar aufkündigen, und Timo Soini solle als Finanzminister in die Regierung eintreten. Die Konservative Partei unter Jyrki Katainen schwenkte daraufhin auf das in der finnischen Verhandlungsdemokratie übliche Muster einer Großen Koalition um, in der sechs Parteien unterschiedlichster parteipolitischer Färbung zusammen fanden - eine » anything goes « Regierung in den Worten von David Arter (2011, S. 1294). Soini brandmarkte diese Koalition unmittelbar nach Abschluss des sehr kurzen und wenig aussagekräftigen Koalitionsvertrages als eine »Koalition der Verlierer « (D. Arter 2011, S. 1293-1295; D. Arter 2015).

Trotz ökonomischer Krise und weiteren Mobilisierungserfolgen der PS aus der Opposition heraus verlief der Wahlkampf 2015 unaufgeregt. Finnland konnte bis 2015 kaum als ein hervorstechendes Einwanderungsland bezeichnet werden. So dominierten ökonomische Themen den Wahlkampf, kaum Fragen der Migration oder der finnischen Kultur. Trotz dieses eher ökonomischen Wahlkampfs - und aufgrund einer Eigenheit des finnischen Wahlrechts (vgl. S. Jochem 2016) - erlangte die PS mehr Stimmen als die Konservative Partei und sie wurde so nach der Zentrumspartei zweitstärkste Partei im bürgerlichen Lager; sie erreichte sogar mehr Stimmen und Mandate als die finnischen Sozialdemokraten (SDP). Migration und Kultur waren die wichtigsten Themen der PS im Wahlkampf. Die Konkurrenten aus dem bürgerlichen Lager sowie die SDP unterließen es, diese Themen aufzunehmen oder gar ihre eher liberalen Positionen zu revidieren. Damit gelang es der PS, als einzige Partei im Wahlkampf wahrgenommen zu werden, die sich - wenngleich sehr vereinfachend und diskriminierend - mit den Themen der Migration und der kulturellen Selbstbestimmung auseinandersetze.

Nach diesem Wahlerfolg der PS und dem offenen Prozess einer Regierungsbildung kam eine Regierungsbeteiligung der PS kaum überraschend. Obwohl Juha Sipilä, der Spitzenkandidat der Zentrumspartei (KESK) und späterer Ministerpräsident, alle Parteien auf einen 15-Fragen-Katalog antworten ließ, entschied sich die stärkste Fraktion des finnischen Parlaments rasch für eine »minimal-winningcoalition « aus Zentrumspartei, PS und Konservativer Partei (KOK). 
Insgesamt wurden im finnischen Parlament keine oder nur sehr niedrige Hürden für eine Kommunikation oder Kooperation der etablierten Parteien mit der PS aufgebaut. Dies kann auch auf den konsensualen Charakter des finnischen Parteienwettbewerbs in der Demokratie der Großen Koalitionen in Europa zurückgeführt werden. Und es kann auf die Führungsstrategie von Timo Soini zurückgeführt werden, der sich in der Öffentlichkeit immer als verhandlungsbereiten und hemdsärmeligen Vertreter der Interessen der ländlichen Bevölkerung darstellte. ${ }^{12}$ In der Öffentlichkeit und bei politischen Konkurrenten der PS wurde sicherlich auch gehofft, mit einer Regierungsbeteiligung die PS einem Realitätstest zu unterziehen, um so den »Drachen zu zähmen « (Kuisma und Nygård 2017, S. 76).

Damit geht einher, dass die PS lange Zeit eine Ein-Personen-Veranstaltung war, Timo Soini als charismatische Persönlichkeit die Partei für alle sichtbar führte. Dieser Führungsanspruch führte allerdings im Falle der PS - anders als in den Gründungsphasen der RechtspopulistInnen in Dänemark und in Norwegen dazu, dass die Partei sich rasch eine solide Organisation gab und auch auf lokaler Ebene bestrebt war, Persönlichkeiten an die Partei zu binden (vgl. D. Arter 2013). Dabei half der PS das finnische Wahlrecht, da sie lokaler oder nationaler Prominenz - also Außenseitern des politischen Betriebs - durch das personalisierte Verhältniswahlrecht den Einzug ins Parlament ermöglicht. Für die PS wurden z. B. 2011 eine Popsängerin (Ritva Elomaa), ein Rocksänger (Pertti Virtanen) sowie ein im Land bekannter Langstreckenläufer (Toivo Juha Väätainen) ins Parlament gewählt (vgl. D. Arter 2014). Diese »buntere« personelle Besetzung kann jedoch Probleme bei der Herstellung parlamentarischer und parteilicher Geschlossenheit verursachen.

Zur Spaltung der PS kam es nach einem internen Putsch im Sommer 2017. Nachdem sich die Partei in der Regierungsverantwortung in ihren drei Hauptzielen (keine monetäre Unterstützung der EU für Griechenland, keine Kürzungen im Sozialstaat, Einschränkung der Einwanderung) nicht durchsetzen konnte, kam es innerhalb der Partei zu immer stärkerer Kritik an der Parteiführung, vor allem vom Jugendverband der Partei. Die Umfragewerte sanken, und als bei der Kommunalwahl die Partei nur noch 8,8 \% der Stimmen erreichen konnte, kam es zum freiwilligen Rückzug Timo Soinis aus der Parteiführung. Mit dem Hardliner Jussi Halla-aho, er wurde bereits für Volksverhetzung bestraft, wurde ein populärer und in den digitalen Medien sicher auftretender Kritiker der Migration und des Islams als Parteivorsitzender gewählt.

12 Es ist bezeichnend, dass Timo Soini im Wahlkampf eine Koalition der PS mit dem Zentrum (KESK) und den Sozialdemokraten bevorzugte (vgl. A.-C. Jungar 2017, S. 73). 
Ministerpräsident Juha Sipilä (KESK) und die Konservative Partei kündigten daraufhin die Regierungszusammenarbeit mit der PS auf. Um diese Situation aufzulösen, verließen alle Regierungsmitglieder der PS die Partei und gründeten mit der Blauen Zukunft eine neue Partei (SIN). Die SIN sicherte zwar die parlamentarische Mehrheit für die Koalition. Gleichwohl wird sie in Meinungsumfragen deutlich hinter der PS eingestuft. Die Partei wird nur von zwei bis drei Prozent der finnischen Bevölkerung als Wahlabsicht angegeben, wohingegen die PS zwischen sieben und zehn Prozent fluktuiert. ${ }^{13}$ Den finnischen RechtspopulistInnen ist es bislang nicht gelungen, den sozialdemokratisch-libertären Konsens in der wohlfahrtsstaatlichen Migrationspolitik zu verändern. Im Unterschied zu den direkt oder indirekt regierenden Schwesterparteien in Norwegen und in Dänemark führte die Regierungsbeteiligung der PS in Finnland zu einer Spaltung der Partei sowie zum Rückgang rechtspopulistischer Mobilisierung.

\section{Schweden}

Die RechtspopulistInnen in Schweden können bislang kaum auf eine Regierungsbeteiligung hoffen; gleichwohl gelangten die Schwedendemokraten (SD) mitunter in die Rolle eines Züngleins an der Waage im Parteienwettbewerb Schwedens, der seit den späten 199oer Jahren immer deutlicher ein Wettbewerb zwischen politischen Lagern wurde. Ebenso ist zu betonen, dass die Einstellung der Bevölkerung zur außernordischen Einwanderung sehr offen und positiv ist. Zumindest ist in Umfragen aus den Jahren 2014 und 2015 des European Social Surveys in keinem anderen Land Europas die Einstellung zur Migration so positiv wie in Schweden (vgl. A. Widfeldt 2017, S. 134). Dazu kommt, dass das Thema der Migration und Integration - anders als in Finnland - auch zu Beginn der rechtspopulistischen Repräsentation im Parlament nicht allein von den Schwedendemokraten aufgegriffen wurde, sondern in fast gleicher Ausprägung (allerdings mit verkehrten Vorzeichen) von der Sozialdemokratie (SAP) (vgl. A. Widfeldt 2017, S. 136). Insofern findet in Schweden ein vehementer Kampf zwischen RechtspopulistInnen und Sozialdemokratie um die Deutungshoheit von Migration in der Öffentlichkeit statt.

Die Schwedendemokraten gründen auf der kurzlebigen Schwedenpartei, die sich ihrerseits aus rechten Bewegungen und Splittergruppen speiste. Diese Bewegungen waren an der Grenze des Rechtsextremismus und zum Teil darüber hinaus verortet. Der erste Vorsitzende der SD, Anders Klarström, war mit der Nor-

13 Die Umfragewerte beruhen auf Angaben des staatlichen Fernsehens in Finnland: https:// svenska.yle.fi/artikel/2018/05/03/yles-partimatning-samlingspartiet-backar-men-forbliranda-landets-storsta-parti (Zugriff: 7. 05. 2018). 
dischen Reichspartei verbunden, die als nationalsozialistische Partei eingestuft werden kann (vgl. A. Widfeldt 2017, S. 138). ${ }^{14}$ Zudem zeichnete sich das parlamentarische Auftreten der SD als sehr polternd und gewalttätig aus. Diese Faktoren führten dazu, dass die etablierten Parteien Schwedens seit Gründung der SD und vor allem nach dem parlamentarischen Durchbruch der SD einen »cordon sanitaire « aufbauten und bis heute beibehalten. Insofern war die Migrationspolitik kaum ein Thema, das zwischen dem linken und dem bürgerlichen Lager für große Konfrontationen sorgte.

Die Flüchtlingskrise in Europa und vor allem der politische Schwenk Dänemarks, die Flüchtlinge auf dem Weg nach Schweden nicht zu erfassen, führte zu einer extremen Zuspitzung der migrationspolitischen Debatte in Schweden. Während die SD jedoch den raschen Anstieg von Asylanträgen im Sommer 2015 zum Anlass nahm, ihre nationalistische Position in immer gereizterem Ton in der Öffentlichkeit zu verbreiten, näherten sich die anderen Parteien in einer zwar restriktiven, aber immer noch liberalen Position in der Migrationspolitik einander an.

Die rot-grüne Minderheitsregierung sah sich im Juni 2016 gezwungen, Einschränkungen im Bereich der Asylpolitik zu verabschieden. Damit wurde bezweckt, dass die EU sich für eine europaweite Verteilung der Flüchtlinge einsetzen sollte - hier suchte die damalige Regierung den Schulterschluss mit der deutschen Regierung. Bis auf den heutigen Tag versucht die rot-grüne Regierung in Stockholm, eine europäische Lösung in der Flüchtlingspolitik herbeizuführen.

Allerdings sieht Carly Elizabeth Schall (2016) im Regierungswechsel von 2006 die zentrale Zäsur in der schwedischen Migrationspolitik. Dieser Regierungswechsel und die Mehrheitsregierung einer bürgerlichen Allianz für Schweden - bestehend aus Konservativer Partei (M), der Liberalen Volkspartei (seit 2015 Liberale Partei), der Zentrumspartei (C) und Christdemokraten (KD) - sei deshalb so bedeutsam, da erstmals glaubwürdig und mit Erfolg eine bürgerliche Alternative zur sozialdemokratischen Hegemonie in Schweden möglich wurde. Dieser »lange, langsame « Tod der SAP (vgl. C. E. Schall 2016, S. 199) habe es ermöglicht, dass die SAP nicht mehr die Hoheit über die Deutung von "Swedishness « hatte. Und dies hätte den Raum geöffnet für ethnische Differenzierungen und - wie in Dänemark und Norwegen seit langer Zeit beobachtbaren - Forderungen nach einem Wohlfahrtschauvinismus.

Ohne Zweifel ist die Wahl von 2006 eine bedeutsame Zäsur für die schwedische Migrationspolitik. Gleichwohl kann der Erfolg der SD nicht nur auf die Schwäche der SAP zurückgeführt werden. Dieses Argument übersieht, dass zum einen die Dynamiken der europäischen Integration in Schweden immer stärker

14 Der heutige Parteivorsitzende der Schwedendemokraten, Per Jimmie Åkesson, war übrigens ein früheres Mitglied der Konservativen Partei (M). 
auch Widerspruch zur dominanten Politik auslösten. Und zudem konnte die SD den politischen Raum erst dann für sich nutzbar machen, als die Konservative Partei und die Christdemokraten nachhaltig ihre Positionen nach links verschoben - und so erst den programmatischen Raum für die SD öffneten (vgl. Rydgren und van der Meiden 2016).

Tatsächlich zwang die parlamentarische Repräsentation der SD im Reichstag beide Lager zu blockübergreifenden Koalitionen nach der Wahl von 2010, in der kein Lager mehr alleine eine Mehrheit erreichen konnte. Allerdings versuchte der konservative Ministerpräsident Fredrik Reinfeldt unmittelbar nach der Wahl, die Grüne Partei ins bürgerliche Lager einzubeziehen und als Unterstützungspartei für die bürgerliche Allianz zu gewinnen. Darin war er aber nicht erfolgreich. Jedoch unterstützte die Grüne Partei Reformen der Migrationspolitik, wohingegen die SAP auch Reformen der Außen- und Sicherheitspolitik mittrug. Insgesamt kam es jedoch gegen Ende der Legislaturperiode zu immer stärkeren BlockadeErscheinungen (vgl. S. Jochem 2011).

Diese Blockade wurde auch durch die Wahl 2014 nicht grundsätzlich aufgelöst. Zwar kam es zu einem Regierungswechsel und zur Bildung einer rot-grünen Minderheitsregierung (unterstützt anfangs von den Linkssozialisten). Rasch wurde aber deutlich, dass der Lagerwettbewerb zu einer Blockade des effektiven Regierens führt. Die SD unterliefen informelle Traditionen des schwedischen Minderheitsparlamentarismus und stimmten bei der Verabschiedung des Budgets 2015 nicht für den eigenen Entwurf, sondern für den Entwurf der bürgerlichen Allianz. Damit hatte die frisch gewählte Regierung ihr erstes Amtsjahr mit einem Budget zu bestreiten, das ihr von der Opposition aufgezwängt wurde. Obwohl die Situation ausweglos erschien, entschied sich der sozialdemokratische Ministerpräsident Stefan Löfven, die Regierung nicht aufzulösen, sondern die Regeln des Minderheitsparlamentarismus zu verändern. Die sogenannte Dezember-Übereinkunft sah vor, dass oppositionelle Parteien das Budgetrecht der Minderheitsregierung beachten sollen, und es wurden lagerübergreifende Vereinbarungen in zentralen Politikfeldern verabredet (vgl. S. Jochem 2015). Allerdings hielt diese Übereinkunft anstatt der anvisierten acht Jahren gerade einmal neun Monate. Die Christdemokraten zogen sich aus strategischen Gründen zurück, die Konservative Partei folgte ihr rasch danach. Insofern zeigt sich, wie prekär die schwedische Verhandlungsdemokratie und die schwedische Form des Minderheitsparlamentarismus sind.

Eine abweichende Interpretation wird von Lindvall et al. (2017) vertreten. Allerdings werden in dieser Studie die reinen Kooperationen gezählt, ohne deren Bedeutung und politische Relevanz zu berücksichtigen. Denn es wird hier nicht argumentiert, dass die Regierungstätigkeit in Schweden durch die SD vollständig lahmgelegt wird. Es wird lediglich argumentiert, dass kein Lager mehr seine 
anvisierte und im Wahlkampf beworbene Politik durchsetzen kann; in bedeutsamen Politikfeldern werden zudem die Kompromisse durch eine Verschiebung der Reform ersetzt. Insofern kann auch die große Erwartung vor der Wahl zum Reichstag im Herbst 2018 erklärt werden, da beide Lager bestrebt sind, die interne Geschlossenheit zu maximieren und gleichzeitig die parlamentarische Mehrheit anzustreben.

Die vorsichtige Annäherung der ehemaligen Vorsitzenden der Konservativen Partei, Anna Kinberg Batra, an die SD war nicht erfolgreich. Bis Dezember 2016 schloss sie noch vehement eine wie auch immer geartete Kooperation mit der SD aus. Im Januar 2017 schloss sie dann allerdings erstmals eine Kooperation mit der SD nicht aus, um so die rot-grüne Regierung zu stürzen und in gewissen Politikfeldern Übereinkünfte zu erzielen. Diese Annäherung an die SD sowie ihre anfänglich Unterstützung für die Dezember-Übereinkunft führten zu zunehmender Kritik in der Partei, woraufhin sie im August 2017 vom Parteivorsitz zurücktrat; im Oktober 2017 wurde Ulf Kristersson zum Parteivorsitzenden gewählt.

Insofern konnte die SD die Migrationspolitik in Schweden noch nicht zur Gänze verändern. Gleichwohl stört sie den schwedischen Minderheitsparlamentarismus nachhaltig. Die Migrationspolitik näherte sich einer einschränkenden Praxis wie in Dänemark und Norwegen an, allerdings sind die Regeln in Schweden noch deutlich freizügiger als in Dänemark (vgl. Brochmann und Hagelund 2015). Im Wahlkampf 2018 revidierte die SAP im April ihre liberale Position und sie räumte - zur Verwunderung und zum Ärgernis der Grünen Partei - ein Zugehen der SAP auf Forderungen der bürgerlichen Allianz ein. Dies führte in der ersten TVDebatte der Spitzenkandidaten zur beachtlichen Situation, dass die diametral entgegengesetzten programmatischen Pole des schwedischen Parteienwettbewerbs die Möglichkeit punktueller Übereinkünfte in der Migrationspolitik nicht mehr ausschließen wollen - was für die Zukunft vor allem weitere Einschränkungen bedeuten würde (vgl. E. Stenberg 2018).

\section{Gründe und Konsequenzen des rechtspopulistischen Erfolgs im Norden}

Die RechtspopulistInnen des europäischen Nordens sind nicht nur gekommen, um zu bleiben; sie bleiben auch, um nicht nur zu protestieren, sondern um zu regieren und so die nordischen Volksheime in ihrem Sinne zu reformieren. Trotz programmatischer Unterschiede im Detail (vgl. A.-C. Jungar 2017) zwischen der Dänischen Volkspartei (DF), der norwegischen Fortschrittspartei (FrP), den Wahren Finnen (PS) oder den Schwedendemokraten (SD) fordern alle vier rechtspopulistischen Parteien den wohlfahrtsstaatlichen Status quo sowie eingeübte 
Routinen der Konsensfindung in den nordischen Demokratien heraus. In diesem Beitrag konnte allerdings gezeigt werden, dass sich die demokratischen Möglichkeitskorridore in den Ländern für eine rechtspopulistische Mobilisierung und Reformpolitik deutlich unterscheiden und die gesellschaftliche Basis rechtspopulistischer Parteien im Norden unterschiedlich ausgeprägt ist (vgl. A. Widfeldt 2018).

Minderheitsregierungen bieten spezifische Möglichkeiten, aber auch Grenzen für rechtspopulistische Politik. Die Dänische Volkspartei konnte als Mehrheitsbeschafferin bürgerlicher Minderheitsregierungen, eingebunden in feste Unterstützungsverträge, von 2001 bis 2011 sowie seit 2015 in sehr großem Ausmaß ihre Politikziele realisieren. Dänemark steht folglich im nordischen Kontext für eine rigorose Regulierung und Eindämmung der Migrationspolitik sowie für einen fortschreitenden Wohlfahrtschauvinismus, also einer Differenzierung sozialpolitischer Leistungen nach ethnischer Zugehörigkeit und staatsbürgerlichem Status (vgl. A.-H. Bay et al. 2013; J. G. Andersen 2007). Insbesondere der dänische Fall zeigt, dass die nordischen, von der Sozialdemokratie geprägten Wohlfahrtsstaaten nicht gegen eine solche Dualisierung gefeit sind, wie Jeroen van der Waal et al. (2013) argumentieren.

Die Grenzen des Regierens in Minderheitsposition erfuhr die norwegische Fortschrittspartei. Ihre ambitionierten Reformpläne scheiterten in weiten Teilen am Veto der Unterstützungsparteien. Durch den Vergleich zwischen Dänemark und Norwegen wird deutlich, dass Unterstützungsparteien im Minderheitenparlamentarismus entscheidend für den Reformprozess sind; dies kann die DF für ihre Ziele nutzen, die FrP wird hingegen dadurch in ihren Zielen eingeschränkt. Gleichwohl gelang es der FrP ebenfalls, die Migrationspolitik restriktiver auszugestalten, allerdings (noch) in deutlich geringerem Ausmaß als dies in Dänemark der Fall ist.

Die Schwedendemokraten können bislang nicht von schwedischem Minderheitsparlamentarismus profitieren, sie werden aber auch nicht dadurch eingeschränkt. Sie sind im Lagerwettbewerb Schwedens oft das Zünglein an der Waage, können Reformambitionen sowohl des linken als auch des bürgerlichen Lagers blockieren (vgl. abweichend zu dieser Interpretation J. Lindvall et al. 2017). Da die anderen Parteien die SD (noch) in einem »cordon sanitaire « einhegen, erschwert sich die Mehrheitsbildung im Parlament. Und weder ist es dem bürgerlichen Block bislang gelungen, die Grüne Partei zur verlässlichen Kooperation zu bewegen, noch gelang dies den Sozialdemokraten mit den Mitteparteien. Eine Entschärfung der minderheitsdemokratischen Falle bei Lager-Wettbewerb - das DezemberÜbereinkommen - ist rasch gebrochen worden. Allerdings zeigt das schwedische Beispiel auch, dass die Kommunikation der Migrationsfrage von allen Parteien aufgegriffen wird, vor allem von der dominanten Sozialdemokratie. Damit kann dieses Thema nicht von den Schwedendemokraten als Alleinstellungsmerkmal 
verwendet werden. Gleichwohl nähert sich Schweden unter einer rot-grünen Regierung den restriktiven Regeln der Migration an, wenn auch deutlich zögerlicher als Norwegen oder gar Dänemark. Zumindest in Schweden wird die Regulierung der Migration noch in einem europäischen Kontext gesehen.

Die Wahren Finnen konnten auch in Regierungsverantwortung ihre Ziele in der Migrationspolitik nicht realisieren. Im Gegenteil führte die Verantwortung notwendiger Kompromisse in einer Koalitionsregierung dort dazu, dass sich die Partei gespalten und insgesamt an Rückhalt in der Wählerschaft eingebüßt hat. Daher konnte die rechtspopulistische Mobilisierung in Finnland bislang kaum eine Auswirkung auf die Migrationspolitik oder den Wohlfahrtsstaat haben.

Gleichwohl findet in allen vier Ländern ein Kulturkampf statt. Die Frage der Nation und der Gemeinschaft in den Volksheimen ist virulent geworden (vgl. allgemein D. Lehnert 2013, sowie für Skandinavien B. Henningsen 2013). Rechtspopulistische Mobilisierungserfolge haben einen eindeutigen Einfluss auf die öffentliche Debatte zur gemeinschaftlichen Selbstverständigung in den nordischen Ländern. Es ist nicht nur der empörte, gereizte Kommunikationsstil, der mit den RechtspopulistInnen Einzug in die nordischen Demokratien hielt (vgl. B. Pörksen 2018). Es sind auch identitäre Vorstellungen von Volksgemeinschaft sowie eine undifferenzierte Kritik an politischen Eliten, die auf die anderen Parteien ausstrahlen. Dies sind die Herausforderungen (nicht nur) für die nordischen Demokratien bzw. für deren Institutionen und Vorstellungen solidarischer Gemeinschaft. Daher sind die RechtspopulistInnen eine Herausforderung unseres Verständnisses von gemeinschaftlicher und solidarischer Demokratie (vgl. W. Müller 2016; F. Decker et al. 2015), keineswegs nur eine Belebung demokratischer Routinen. Die erfolgreichen RechtspopulistInnen in Dänemark und Norwegen zeigen durch ihre Reformpolitik, dass sie Wohlfahrtschauvinismus und restriktive Migrationspolitiken umsetzen, um so der Pluralität in entgrenzten und komplexen Gesellschaften eine alternative Ordnung entgegen zu setzen.

\section{Literatur}

Andersen, Jørgen Goul. 2007. Restricting Access to Social Protection for Immigrants in the Danish Welfare State. Benefits 15: 257-269.

Arter, David. 2016. Scandinavian Politics Today, 3rd ed. Manchester (UK): Manchester University Press.

Arter, David. 2015. A >Pivotal Centre Party< Calls the Shots: The 2015 Finnish General Election. West European Politics 38: 1345-1353.

Arter, David. 2014. Clowns, >Alluring Ducks` and >Miss Finland 2009«: The Value of >Celebrity Candidates $<$ in an Openlist PR Voting System. Representation 50 (4): 453-470. 
Arter, David. 2013. The >Hows «, not the >Whys « or the > Wherefores $\triangleleft$ The Role of Intraparty Competition in the 2011 Breakthrough of the True Finns. Scandinavian Political Studies 36: 99-120.

Arter, David. 2011. Taking the Gilt off the Conservatives' Gingerbread: The April 2011 Finnish Election. West European Politics 34: 1284-1295.

Bay, Ann-Helén, Henning Finseraas, und Axel West Pedersen. 2013. Welfare Dualism in Two Scandinavian Welfare States: Public Opinion and Party Politics. West European Politics 36 (1): 199-220.

Betz, Hans-Georg. 1993. The New Politics of Resentment: Radical Right-Wing Populist Parties in Western Europe. Comparative Politics 25: 413-427.

Brochmann, Grete, und Anniken Hagelund. 2015. Migrationspolitik in den skandinavischen Wohlfahrtsstaaten. In Bernd Henningsen et al. 2015, 173-197.

Christiansen, Flemming Juul. 2017. Conflict and co-operation among the Danish mainstream as a condition for adaptation to the populist radical right. In Odmalm und Hepburn 2017, 49-70.

Decker, Frank, Bernd Henningsen, und Kjetil Jakobsen (Hrsg.). 2015. Rechtspopulismus und Rechtsextremismus in Europa. Die Herausforderung der Zivilgesellschaft durch alte Ideologien und neue Medien. Baden-Baden: Nomos Verlag.

Etzold, Tobias. 2016. Flüchtlingspolitik in Nordeuropa. Die nordischen Länder gleichen ihren Kurs immer stärker an, doch Unterschiede bleiben (Stiftung Wissenschaft und Politik: SWP Aktuell 78, Dezember 2016). Berlin.

Fischer, Peter, und Thomas Straubhaar. 1994. Integration und Migration in einem Gemeinsamen Markt, Bern/Stuttgart: Haupt Verlag.

Förster, Christian, Josef Schmid, und Nicolas Trick. 2014. Die nordischen Länder. Politik in Dänemark, Finnland, Norwegen und Schweden. Wiesbaden: Springer VS.

Green-Pedersen, Christoffer, und Simon Otjes. 2017. A hot topic? Immigration on the agenda in Western Europe. Party Politics (online first).

Haffert, Lukas, und Philip Mehrtens. 2013. From Austerity to Expansion? Consolidation, Budget Surpluses, and the Decline of Fiscal Capacity (Max-Planck-Institut für Gesellschaftsforschung: MPIfG Discussion Paper 13/16). Köln.

Henningsen, Bernd. 2013. Gemeinschaft versus Staat, Nation versus Europa. Nordeuropäische Gemeinschaftskonstruktionen und die modernen Traditionsbrüche. In Gemeinschaftsdenken in Europa. Das Gesellschaftskonzept »Volksheim " im Vergleich 1900-1938, hrsg. von Detlef Lehnert, 39-72, Köln: Böhlau Verlag.

Henningsen, Bernd, Sven Jochem, und Siegfried Frech (Hrsg.). 2015. Das politische Skandinavien. Gesellschaft, Wirtschaft, Politik \& Kultur. Schwalbach/Ts.: Wochenschau Verlag.

Jochem, Sven. 2018. Radikal-nationalistische Regierungspolitik - Die norwegische Fortschrittspartei (unveröffentlichtes Manuskript).

Jochem, Sven. 2016. Die Parlamentswahl 2015 in Finnland. Herausforderungen für die Verhandlungsdemokratie. Zeitschrift für Parlamentsfragen 47 (1): 102-117.

Jochem, Sven. 2015: Die schwedische Reichstagswahl 2014. Regierungswechsel und Regierungskrise im schwedischen Minderheitsparlamentarismus. Zeitschrift für Parlamentsfragen 46 (3): 494-504.

Jochem, Sven. 2012. Die politischen Systeme Skandinaviens. Wiesbaden: Springer VS. 
Jochem, Sven. 2011: Die schwedische Reichstagswahl vom 19. September 2010. Zur Logik einer sich auflösenden sozialdemokratischen Hochburg. Zeitschrift für Parlamentsfragen 42 (1): 117-130.

Jörke, Dirk, und Veith Selk. 2017. Theorien des Populismus zur Einführung. Hamburg: Junius.

Jungar, Ann-Cathrine. 2017. Populism i Norden. Från marginalen mot den politiska mittfåran. Helsinki: Arena.

Jungar, Ann-Cathrine, und Anders Ravik Jupskås. 2014. Populist Radical Right Parties in the Nordic Region: A New and Distinct Party Family? Scandinavian Political Studies 37 (3): 215-238.

Kitschelt, Herbert. 2018. Party Systems and Radical Right-Wing Parties. In Jens Rydgren 2018, 166-199.

Kuisma, Mikko, und Mikael Nygård. 2017: Immigration, Integration and the Finns Party: Issue-ownership by Coincidence or by Stealth? In Odmalm und Hepburn 2017, 71-89.

Kvist, Jon, Johan Fritzell, Bjørn Hvinden, und Olli Kangas (Eds.). 2012. Changing Social Equality: The Nordic Welfare Model in the 21st Century. Bristol (UK): Policy Press.

Lehnert, Detlef (Hrsg.). 2013. Gemeinschaftsdenken in Europa. Das Gesellschaftskonzept » Volksheim « im Vergleich 1900-1938, Köln: Böhlau Verlag.

Lindvall, Johannes, Hanna Bäck, Carl Dahlström, Elin Naurin, und Jan Teorell. 2017. Samverkan och strid i den parlamentariska demokratin. SNS Demokratirapport 2017. Stockholm: SNS.

Mehrtens, Philip. 2014. Staatsschulden und Staatstätigkeit. Zur Transformation der politischen Ökonomie Schwedens, Frankfurt a. M./New York: Campus Verlag.

Müller, Werner. 2016: Was ist Populismus? Ein Essay. Berlin: Suhrkamp Verlag.

Nedergaard, Peter, und Anders Wivel (Eds.). 2018. The Routledge Handbook of Scandinavian Politics. Abingdon (Oxon, UK)/New York: Routledge.

Odmalm, Pontus, und Eve Hepburn (Eds.). 2017. The European Mainstream and the Populist Radical Right. London: Routledge.

Pörksen, Bernhard. 2018. Die große Gereiztheit. Wege aus der kollektiven Erregung. München: Carl Hanser Verlag.

Rydgren, Jens (Ed.). 2018. The Oxford Handbook of the Radical Right. Oxford (UK): Oxford University Press.

Rydgren, Jens. 2017. Radical right-wing parties in Europe. What's populism got to do with it? Journal of Language and Politics 16 (4): 485-496.

Rydgren, Jens, und Sara van der Meiden. 2016. Sweden, Now a Country Like All the Others? The Radical Right and the End of Swedish Exceptionalism (University of Stockholm, Department of Sociology: Working Papers Series No. 25). Stockholm.

Schall, Carly Elizabeth. 2016. The Rise and Fall of the Miracolous Welfare Machine: Immigration and Social Democracy in Twentieth-Century Sweden. Ithaca, NY/London: Cornell University Press.

Stenberg, Ewa. 2018. En partilederdebatt som inte var lik någon annan. Dagens Nyheter vom 6.05. 2018. 
van der Waal, Jeroen, Willem de Koster, und Wim van Oorschot. 2013. Three Worlds of Welfare Chauvinism? How Welfare Regimes Affect Support for Distributing Welfare to Immigrants in Europe. Journal of Comparative Policy Analysis: Research and Practice 15 (2): 164-181.

Widfeldt, Anders. 2018. The Radical Right in the Nordic Countries. In Jens Rydgren 2018, 545-564.

Widfeldt, Anders. 2017. Sweden. From deviant case to populist radical right hotbed? In Odmalm und Hepburn 2017, 131-152.

Widfeldt, Anders. 2015a. Extreme Right Parties in Scandinavia. New York: Routledge.

Widfeldt, Anders. 2015b. Tensions beneath the surface - The Swedish mainstream parties and the immigration issue. Acta Politica 50 (4): 399-416. 